\title{
AVALIAÇÃO DO RESÍDUO AGROINDUSTRIAL DE ACEROLA PARA PRODUÇÃO DE CELULASES POR FERMENTAÇÃO EM ESTADO SÓLIDO
}

\author{
B. C. A. de MÉLO ${ }^{1}$, R. de A. SILVA², G. T. M. KUBO ${ }^{3}$, L. S. CONRADO ${ }^{4}$ e W. SCHIMDELL ${ }^{5}$ \\ ${ }^{1}$ Instituto Federal de Educação, Ciência e Tecnologia do Sertão Pernambucano, Coordenação de \\ Tecnologia em Alimentos \\ ${ }^{2}$ Universidade Federal de Campina Grande, Departamento de Engenharia Química \\ ${ }^{3}$ Universidade Federal de Campina Grande, Departamento de Engenharia Agrícola \\ ${ }^{4}$ Universidade Federal de Campina Grande, Departamento de Engenharia Química \\ ${ }^{5}$ Universidade Federal de Santa Catarina, Departamento de Engenharia Química e de Alimentos \\ E-mail para contato: beatriz.amorim@ifsertao-pe.edu.br
}

\begin{abstract}
RESUMO - Os processos industriais, no geral, além do produto de interesse, geram múltiplas saídas de outros materiais em forma de resíduos e emissões não incorporadas no produto final que geralmente são aceitas como efeito normal no processo de fabricação. Nos últimos anos tem se intensificado o aproveitamento de resíduos agroindustriais, e uma das formas de agregar-lhes valor é submetê-los a processos fermentativos para obtenção de produtos de maior valor agregado e ao mesmo tempo minimizar o seu despejo no meio ambiente. A produção de enzimas a partir de processos fermentativos tem sido vista como uma saída possivelmente sustentável para os resíduos agroindustriais. Dessa forma, este trabalho teve por objetivo avaliar o resíduo agroindustrial de acerola para ser utilizado na produção de celulases através de processos fermentativos em estado sólido. Para isso, inicialmente foi realizada a caracterização físico-química do resíduo, em seguida foram montadas isotermas de sorção de água, e por fim foi realizado um teste preliminar de produção da enzima. A caracterização físico-química mostrou que esse resíduo tem potencial para ser utilizado na produção de celulases em fermentações em estado sólido por apresentar condições favoráveis ao processo de fermentação como pH ácido $(3,54)$ e fonte de carbono representada pelos açúcares redutores $(9,42 \%)$ e pela celulose $(44,30 \%)$. Nas condições estudadas, a atividade enzimática máxima alcançada foi de 1,25 U/g após 216 horas de fermentação.
\end{abstract}

\section{INTRODUÇÃO}

Os processos industriais e agroindustriais, no geral, além do produto de interesse, geram múltiplas saídas de outros materiais em forma de resíduos e emissões não incorporadas no produto final que geralmente são aceitas como efeito normal no processo de fabricação. Nos últimos anos tem se intensificado o aproveitamento de resíduos, especialmente os agroindustriais. Dessa forma, vêm sendo desenvolvidos alguns processos biotecnológicos para utilizar esses materiais na produção de ácidos orgânicos, enzimas e álcool, gerando produtos de grande valor econômico e atendendo à proposta ZERI "Zero Emissions Research Initiative", que estabelece uma mudança de paradigmas no conjunto das atividades 
econômicas, particularmente dos processos de produção industrial. Essa estratégia objetiva a transformação da matéria-prima em bens úteis sem danificar o meio ambiente, colocando os resíduos e emissões como insumos para outros produtos (Israel, 2005).

Os resíduos agroindustriais, constituídos principalmente por cascas e sementes de vegetais, geralmente não recebem a devida atenção, no sentido de serem usados ou reciclados, evitando o desperdício. Isto, possivelmente, ocorre devido à falta de valor comercial desse produto (Soong \& Barlow, 2004). No entanto, vale ressaltar que a casca e as frações da semente de certas frutas exibem elevadas concentrações de substâncias interessantes para certos processos. Uma das formas de agregar valor aos resíduos agroindustriais, no geral, é submetê-los à processos fermentativos para obtenção de produtos de maior valor agregado e ao mesmo tempo minimizar o despejo desses rejeitos no meio ambiente. Dentre outros processos, a produção de enzimas a partir de processos fermentativos tem sido vista como uma saída possivelmente sustentável para os resíduos agroindustriais.

As celulases são enzimas capazes de hidrolisar as ligações $\beta$-1,4-glicosídicas da cadeia da celulose, que é o principal componente da parede celular da biomassa vegetal. Essas enzimas têm uma ampla variedade de aplicações industriais, sendo utilizadas como aditivo no preparo de enzimas digestivas, como componente de detergentes, no clareamento e amaciamento de fibras, no tratamento de águas residuais, entre outros (Bhat \& Bhat, 1997).

A produção de celulases por ação microbiana tem sido foco de muitos estudos com o objetivo de estabelecer as melhores condições para a produção dessas enzimas. Nesse processo de produção da enzima, um microrganismo é utilizado como agente metabolizador de fontes de carbono presentes em um meio de cultivo, de forma que as enzimas são sintetizadas e excretadas (Tavares, 2009).

Dentro desse contexto, este trabalho teve como objetivo avaliar o resíduo agroindustrial de acerola do Sertão Pernambucano para ser utilizado como substrato em processos fermentativos de produção de celulases, minimizando o despejo desses resíduos no meio ambiente e ao mesmo tempo obtendo um produto de maior valor agregado.

\section{MATERIAL E MÉTODOS}

O resíduo de acerola utilizado nesse trabalho foi cedido pela indústria de beneficiamento de frutas NIAGRO - Nichirei do Brasil Agrícola Ltda., localizada no distrito industrial em Petrolina/PE. O preparo do resíduo foi realizado em três etapas: secagem, moagem e armazenamento. A secagem foi realizada em um secador de bandejas com circulação forçada de ar a uma temperatura de $55^{\circ} \mathrm{C}$ até que fosse atingida massa constante. Após o processo de secagem, o resíduo foi então moído em um moinho de facas e por fim foi embalado à vácuo em embalagens de polietileno de alta densidade.

\subsection{Caracterização físico-química}

Como etapa inicial do trabalho, foi realizada uma caracterização físico-química do resíduo de acerola, na sua forma desidratada e moída, com o objetivo de verificar quais os componentes presentes naquele material, de forma que fosse possível avaliar a possibilidade de utilizá-lo como substrato na fermentação em estado sólido para produção de enzimas 
celulolíticas. Todas as análises da caracterização físico-química seguiram as metodologias descritas a seguir e foram realizadas em cinco repetições para que fosse possível a determinação de parâmetros estatísticos, como o desvio padrão e o coeficiente de variação.

Densidade Aparente, Densidade Real, pH e Sólidos Solúveis: as análises foram realizadas seguindo as metodologias descritas em Brasil (2005).

Umidade, Cinzas, Extrativos, Lignina, Holocelulose e Hemicelulose: as análises foram realizadas seguindo as metodologias descritas em Morais et al. (2010).

Granulometria: o perfil granulométrico do resíduo foi determinado seguindo as recomendações da NBR - 7181 da Associação Brasileira de Normas Técnicas (ABNT, 1984).

Porosidade: a porosidade do material foi determinada seguindo a metodologia descrita por Keey (1991).

Açúcares Redutores: a concentração de açúcares redutores foi determinada seguindo a metodologia descrita por Miller (1959).

\subsection{Levantamento das Isotermas de Sorção de Água}

Para o levantamento da isoterma de sorção de água do resíduo de acerola foram preparadas diversas amostras do resíduo com umidades diferentes, de forma a obter-se diferentes atividades de água no mesmo material. Para isso, foram preparadas amostras de $5 \mathrm{~g}$ de resíduo com diferentes volumes de água destilada, variando de 0 a $5 \mathrm{~mL}$ de água destilada para cada $5 \mathrm{~g}$ de resíduo, de modo a simular as condições de incubação de uma fermentação em estado sólido. Após ser umidecida, cada amostra preparada foi levada à geladeira em recipientes herméticos e deixados por um período de 24 horas em repouso para uniformização o meio. Após esse tempo, as amostras foram retiradas da geladeira, deixadas em um dessecador para atingir a temperatura ambiente e em seguida foram realizadas as análises de atividade de água e da umidade de equilíbrio do material. A atividade de água das amostras foi analisada diretamente em equipamento Thermoconstanter Novasina RTD 200 TH2 à 25, 30, 35 e $40{ }^{\circ} \mathrm{C}$ e as análises de umidade de equilíbrio foram realizadas seguindo a metodologia descrita em Brasil (2005) semelhantemente com a utilizada na caracterização físico-química. A partir dos dados de atividade de água e da umidade de equilíbrio, foram construídas as isotermas de sorção do material.

\subsection{Teste Preliminar de Produção de Celulases}

O teste preliminar de produção de celulases por fermentação em estado sólido com o resíduo de acerola foi realizado com o microrganismo Trichoderma reesei com uma concentração de $10^{7}$ esporos/g, a uma temperatura de $30{ }^{\circ} \mathrm{C}$, em erlenmeyers de $250 \mathrm{~mL}$ contendo aproximadamente $20 \mathrm{~g}$ de meio fermentativo, previamente esterilizados, e tampados com tampões de gaze e algodão. $\mathrm{O}$ meio fermentativo foi reumidificado para ter uma umidade inicial de $45 \%$, além de ser enriquecido com uma concentração da fonte de nitrogênio de 1 $\%$. O processo fermentativo foi avaliado ao longo do tempo quanto à umidade, ao $\mathrm{pH}$, aos açúcares redutores e à atividade enzimática, expressa em carboximetilcelulase, até 336 horas de fermentação. 


\section{RESULTADOS E DISCUSSÃO}

\subsection{Caracterização físico-química}

A Tabela 1 apresenta os resultados obtidos da caracterização físico-química do resíduo agroindustrial de acerola, bem como os seus parâmetros estatísticos como o desvio padrão e o coeficiente de variação.

Tabela 1 - Caracterização físico-química do resíduo agroindustrial de acerola.

\begin{tabular}{|c|c|c|}
\hline PARÂMETROS & VALOR & $* \mathbf{C V ~ ( \% )}$ \\
\hline Densidade aparente $(\mathrm{g} / \mathrm{mL})$ & $0,26 \pm 0,00$ & 0,00 \\
\hline Densidade real $(\mathrm{g} / \mathrm{mL})$ & $1,00 \pm 0,00$ & 0,00 \\
\hline Porosidade & 0,74 & - \\
\hline $\mathrm{pH}$ & $3,54 \pm 0,01$ & 0,28 \\
\hline Umidade (\%) & $7,98 \pm 0,21$ & 2,63 \\
\hline Cinzas (\%) & $2,36 \pm 0,05$ & 2,11 \\
\hline Extrativos (\%) & $14,89 \pm 0,95$ & 6,41 \\
\hline Lignina (\%) & $28,03 \pm 0,68$ & 2,42 \\
\hline Holocelulose (\%) & $44,30 \pm 0,65$ & 1,47 \\
\hline Hemicelulose (\%) & 0,48 & - \\
\hline Sólidos Solúveis (\%) & $29,97 \pm 0,20$ & 0,67 \\
\hline Açúcares Redutores (\%) & $9,40 \pm 0,10$ & 1,06 \\
\hline * Coeficiente de Variação (\%)
\end{tabular}

A Tabela 1 mostra que a umidade encontrada no resíduo de acerola, 7,98 \%, permite uma melhor conservação do produto, aumentando o tempo de vida útil, uma vez que reduz a água disponível para a proliferação dos microrganismos e para as reações químicas (Chaves et al., 2004), além de possibilitar o ajuste da umidade do material para ser utilizado em processos fermentativos apenas com adição de água.

O pH encontrado no resíduo de acerola, 3,54, mostra que esse é um resíduo que pode ser classificado como ácido e, por conseguinte, de difícil ataque microbiano. Além disso, essa faixa de $\mathrm{pH}$ é ideal para o desenvolvimento das atividades metabólicas de fungos filamentosos. Souza (2008) estudando a produção de pectinases por fermentação semi-sólida utilizou como substrato o resíduo do maracujá o qual apresentou um pH ácido com um valor de 3,57.

Segundo Fontana et al. (2005), substratos que apresentam concentrações balanceadas de açúcares e pectina, indutor da pectinase, tem mostrado altos rendimentos em enzimas pectinolíticas. Dessa forma, pode-se pressupor que para produção de celulase deva existir também um valor ótimo da relação entre açúcares redutores e a celulose, que é a fonte indutora na produção das celulases. A concentração de açúcares redutores encontrada no resíduo de acerola foi de $9,40 \%$, quantidade essa suficiente para ser utilizada como fonte nutricional para o desenvolvimento de microrganismos em processos fermentativos. E a concentração de celulose (holocelulose) encontrada no resíduo de acerola foi de 44,30 \%, valor este suficiente para induzir a produção de enzimas celulolíticas e elevado se comparado 
com o encontrado por Ferreira et al. (2007) no subproduto da agroindústria do caju que foi de $21 \%$.

Além de outras características físico-químicas, é necessário, avaliar a estrutura física do substrato, sobretudo, quanto ao tamanho das suas partículas e a porosidade, que determinam a área superficial acessível ao microrganismo e uma posterior etapa de extração da enzima em processo sólido-líquido. Na Figura 1 encontra-se o perfil granulométrico do resíduo agroindustrial de acerola.

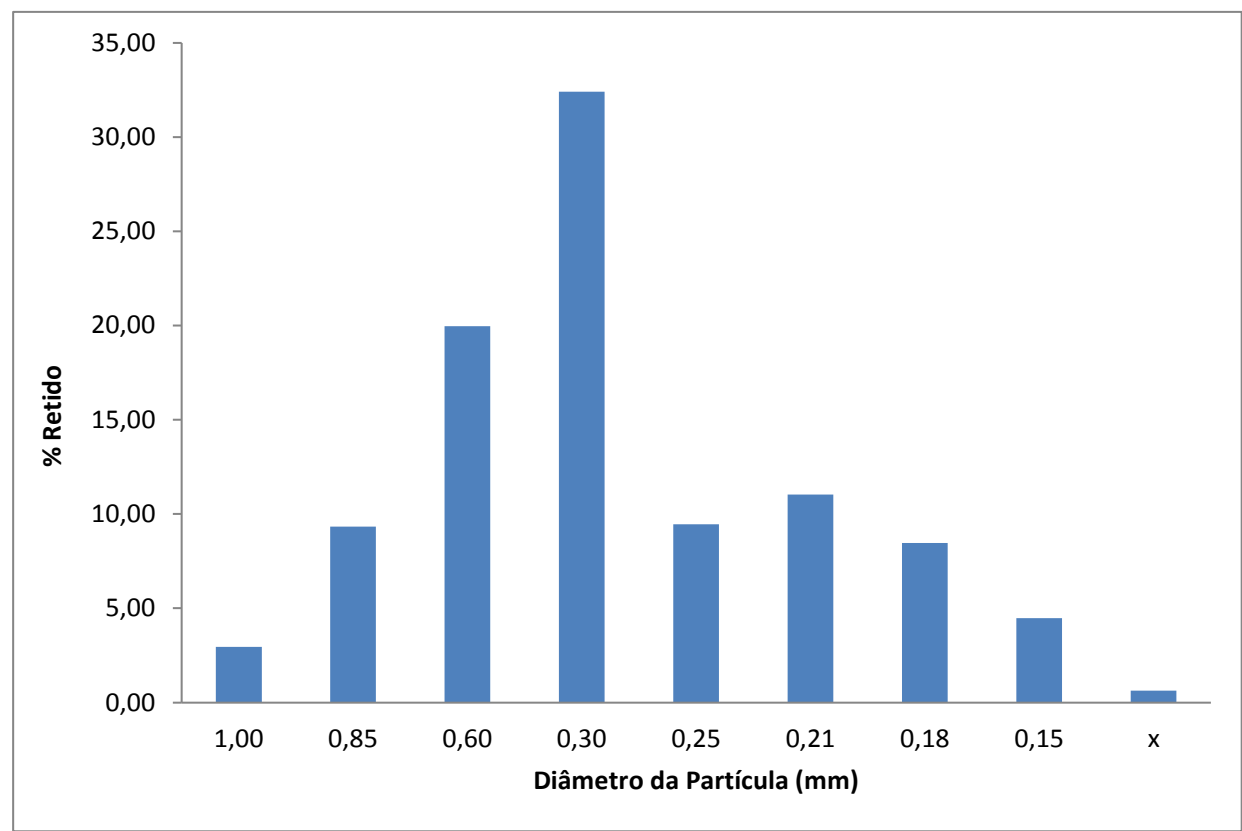

Figura 1 - Perfil granulométrico do resíduo agroindustrial de acerola.

Como pode ser observado pela distribuição granulométrica apresentada na Figura 1, o resíduo de acerola tem a maioria das suas partículas com um diâmetro entre 0,30 e $0,60 \mathrm{~mm}$ e o diâmetro médio das partículas é de aproximadamente $0,40 \mathrm{~mm}$. O diâmetro médio das partículas desse resíduo aproxima-se de outros estudos que utilizaram resíduos agroindustriais, como o de Correia (2004) que estudou o enriquecimento proteico do resíduo de abacaxi e trabalhou com partículas de tamanho maior que 0,42 mm. Tavares (2009), estudando a produção de celulases por fermentação em estado sólido em resíduo de caju utilizou o substrato com partículas de, em média, 0,42 $\mathrm{mm}$.

A porosidade do leito formado por esse resíduo foi de 0,74 , como apresentado na Tabela 1, o que favorece a aeração do sistema, disponibilizando o oxigênio necessário ao desenvolvimento do microrganismo. Além do tamanho das partículas, a porosidade está relacionada com a densidade aparente $\left(0,26 \mathrm{~g} / \mathrm{cm}^{3}\right)$ que revela o quanto o substrato tende a não se compactar completamente, gerando os espaços vazios entre as partículas do substrato, suficientes para respiração e metabolismo por parte do microrganismo.

\subsection{Levantamento das Isotermas de Sorção de Água}

A Figura 2 apresenta as isotermas de sorção de água do resíduo agroindustrial de acerola nas temperaturas de $25,30,35$ e $40{ }^{\circ} \mathrm{C}$. 


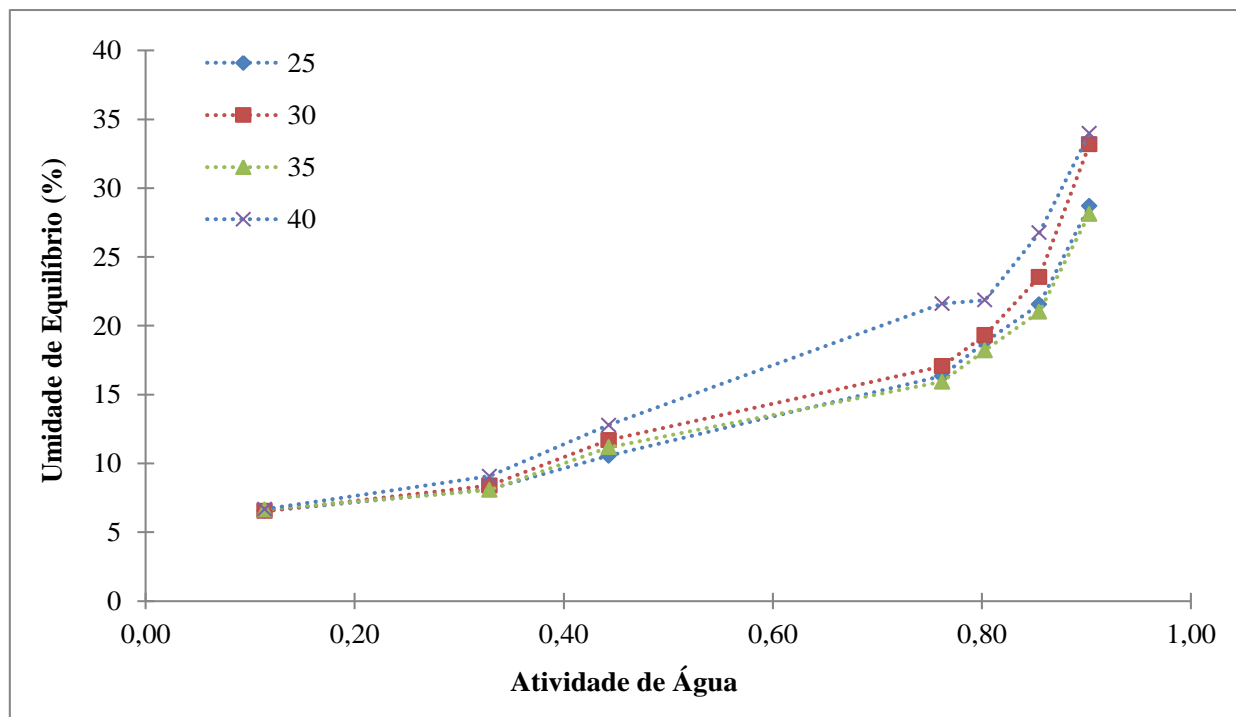

Figura 2 - Isotermas de sorção de água do resíduo de acerola a $25,30,35$ e $40{ }^{\circ} \mathrm{C}$.

Avaliando as isotermas de sorção de água do resíduo de acerola, mostradas na Figura 2, pode-se perceber que, como nos materiais higroscópicos, a umidade de equilíbrio aumenta com o aumento da atividade de água $\left(\mathrm{a}_{\mathrm{w}}\right)$, em todas as temperaturas estudadas. Além disso, observa-se que umidades de equilíbrio a partir de $20 \%$ correspondem a uma atividade de água suficiente para o crescimento de fungos filamentosos para todas as temperaturas.

\subsection{Teste Preliminar de Produção de Celulases}

As Figuras 3 e 4 apresentam os resultados obtidos para umidade, $\mathrm{pH}$, açúcares redutores e atividade celulolítica, expressa em carboximetilcelulase, do teste preliminar de produção de celulases com o resíduo de acerola utilizando o Trichoderma reesei.

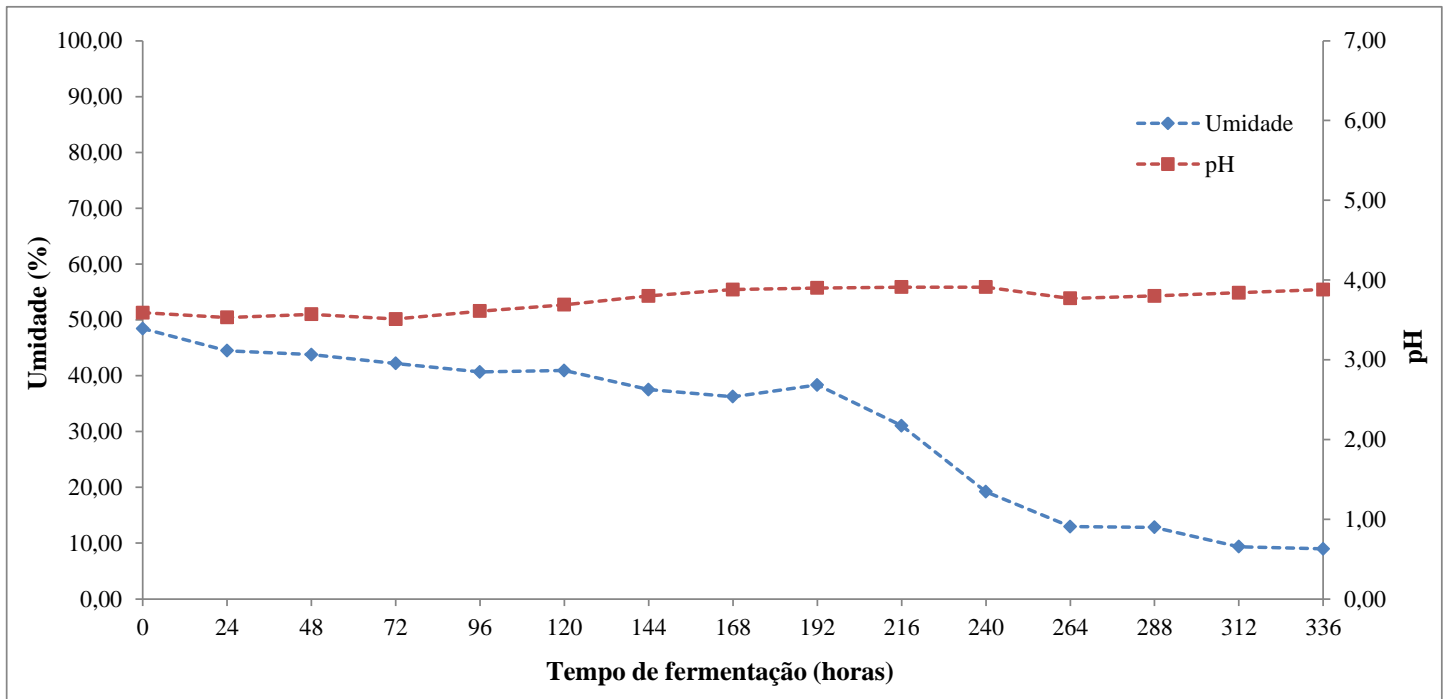

Figura 3 - Perfil cinético da umidade (\%) e o do $\mathrm{pH}$ ao longo do processo de produção de celulases por fermentação em estado sólido com o resíduo de acerola. 


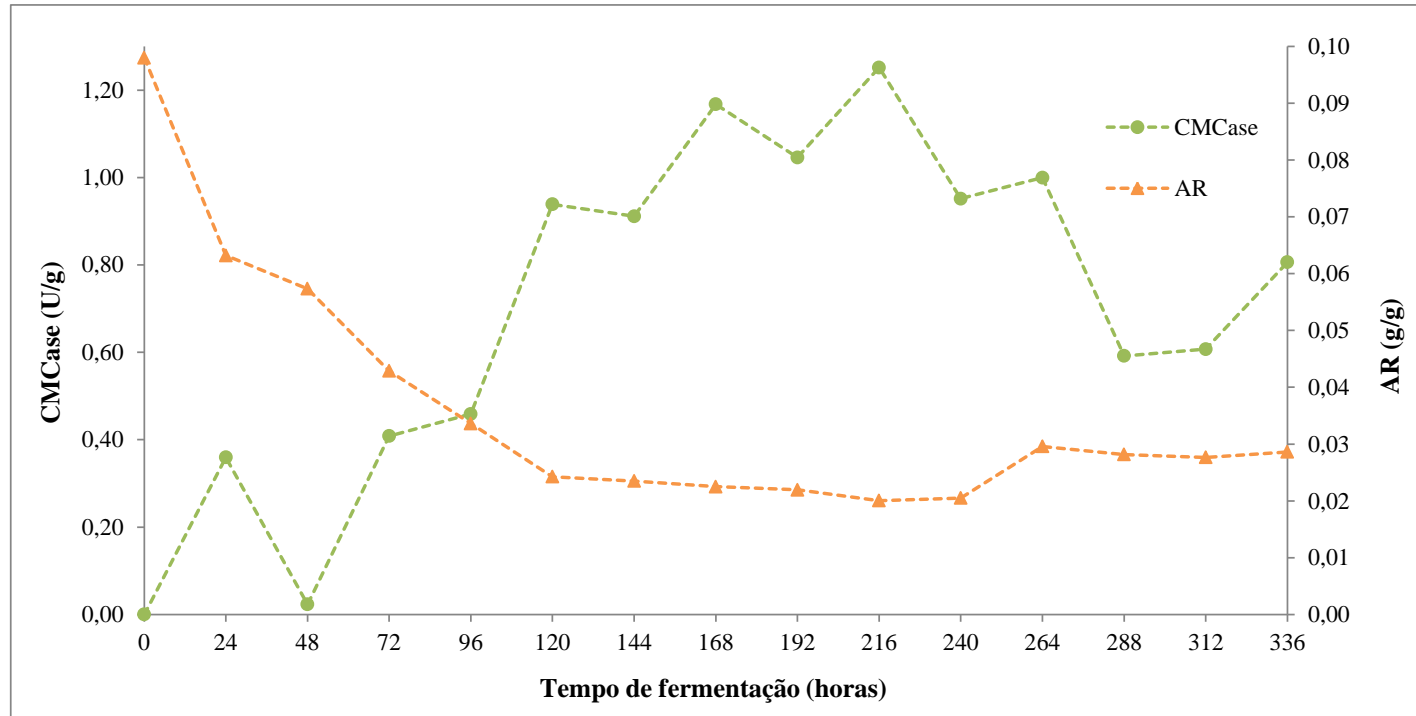

Figura 4 - Perfil cinético da concentração de açúcares redutores $(\mathrm{g} / \mathrm{g})$ e da CMCase (U/g) ao longo da produção de celulases por fermentação em estado sólido com o resíduo de acerola.

Avaliando os resultados apresentados na Figura 3 percebe-se que a umidade do meio diminui consideravelmente ao longo do processo de fermentação, fato este que pode ser justificado pelas atividades metabólicas ocorridas durante o processo. $\mathrm{O} \mathrm{pH}$ manteve-se praticamente constante ao longo de todo o processo fermentativo, sofrendo leves aumentos e diminuições no seu valor, o que pode está associado à produção e assimilação de ácidos orgânicos ocorridas durante a fermentação (Botella et al., 2007).

Como mostrado na Figura 4, os açúcares redutores presentes no resíduo de acerola foram hidrolisados desde o início do processo até 120 horas de fermentação, a partir de onde se manteve constante até o final do processo fermentativo. Além disso, percebe-se que após 24 horas do início do processo já se obteve uma atividade enzimática, expressa em carboximetilcelulase, de 0,36 U/g e a maior atividade alcançada foi de aproximadamente 1,25 U/g após 216 horas de fermentação.

\section{CONCLUSÕES}

A caracterização físico-química mostrou que o resíduo agroindustrial de acerola tem potencial para ser utilizado na produção de celulases em fermentações em estado sólido por apresentar condições favoráveis ao processo de fermentação como um $\mathrm{pH}$ que caracterizam o meio ácido, e por apresentar fontes de carbono representadas pelos açúcares redutores $(9,40$ $\%)$ e pela celulose $(44,30 \%)$.

Além disso, os testes preliminares de produção das celulases utilizando o resíduo de acerola mostraram que, nas condições estudadas, a atividade enzimática máxima alcançada foi de 1,25 U/g após 216 horas de fermentação.

\section{REFERÊNCIAS BIBLIOGRÁFICAS}

ABNT: ASSOCIAÇÃO BRASILEIRA DE NORMAS TÉCNICAS. NBR 7181: Solo Análise Granulométrica, 1984. 
BHAT, M. K.; BHAT, S. Cellulose degradading enzymes and their potencial industrial application. Biotechnology Advances, v. 15, n. 3-4, p. 586-620, 1997.

BOTELlA, C.; DIAZ, A.; ORY, I.; WEBB, C.; BLANDINO, A. Xylanase and pectinase production by Aspergillus awamori on grape pomace in solid state fermentation. Process Biochemistry, v. 42, n. 1, p. 98-101, 2007.

BRASIL, Ministério da Saúde. Agência Nacional de Vigilância Sanitária. Métodos físicoquímicos para análise de alimentos. Brasília: Editora MS, p. 1017, 2005.

CORREIA, R. T. P. Estudo do cultivo semi-sólido de Saccaharomyces cerevisiae e Rhizopus oligosporus em resíduo de abacaxi. 2004. 163f. Tese (Doutorado) - Universidade Federal do Rio Grande do Norte, Natal, RN.

FONTANA, R. C.; SALVADOR, S.; SILVEIRA, M. M. Efeito das concentrações de pectina e glicose sobre a formação de poligalacturonases por Aspergillus niger em meio sólido. In: SIMPÓSIO NACIONAL DE BIOPROCESSOS, 15., Recife, 2005. Anais...Recife: 2005.

ISRAEL M. C., Utilização do Resíduo do Processamento do Palmiteiro para a Produção de Enzimas Hidrolíticas por Fungos do Gênero Polyporus. 2005. 135f. Dissertação (Mestrado em Engenharia Ambiental), Universidade Regional de Blumenau, Blumenau.

KEEY, R. B. Drying of loose and particulate materials. New York: Hemiphere, p. 57, 1991.

MILLER, G. L. Use of dinitrosalicylic acid reagent for determination of reducing sugar. Analytical Chemistry, v. 31, n. 3, p. 426-428, 1959.

MORAIS, J. P. S.; ROSA, M. F.; MARCONCINI, J. M. Procedimentos para análise lignocelulósica. Documento 236, p.54, Campina Grande: Embrapa Algodão, 2010.

PINTO, G. A. S.; BRITO, E. S.; SILVA, F. L. H., SANTOS, S. F. M., MACEDO, G. R. Fermentação em estado sólido: Uma alternativa para o aproveitamento e valorização de resíduos agroindustriais. Revista de Química Industrial, v. 74, p. 17-20, 2006.

SOONG, Y. Y.; BARLOW, P. J. Antioxidant activity and phenolic content of selected fruit seeds. Food Chemistry, London, v.88, p. 411-417, 2004.

SOUZA R. L. A. Produção de pectinases por fermentação semi-sólida utilizando resíduo do maracujá como substrato. 2008. 81f. Dissertação (Mestrado em Engenharia Química), Universidade Federal de Campina Grande, Campina Grande, PB.

TAVARES, M. B. R. Estudo da produção da enzima celulase a partir da matéria lignocelulósica bagaço do caju por fermentação semi-sólida utilizando Aspergillus niger. 2009. 108f. Dissertação (Mestrado em Engenharia Química), Universidade Federal de Campina Grande, Campina Grande, PB.

ZHENG, Z.; SHETTY, K. Cranberry processing waste for solid state fungal inoculants production. Process Biochemistry, v. 33, n. 8, p. 323-329, 2000. 